\title{
Vorrede zur zweiten Auflage.
}

Schon nach wenig mehr als Jahresfrist ist es mir vergönnt, den „Alexandre" zum zweiten Male hinausgehen zu lassen. Die mancherlei Beurteilungen und Kundgebungen, die mir teils auf öffentlichem, teils auf privatem Wege zugegangen sind, beweisen zur Genüge, dass das Werk in der Hauptsache durchaus auf dic richtige Würdigung bei den Deutschen getroffen ist, und dass sehr schnell immer mehrere die an sich für unsere Landsleute so wundersam abschreckende Schale des Alexandriners durchbrochen haben, um mit Freuden hier Blut von unserem Blute, Geist von unserem Geiste zu erkennen. Nur vereinzelt ist mir eine Überschätzung des "Alexandre» vorgeworfen worden. Je nun, jenen "parteiischen Enthusiasmus», ohne den man nun cinmal nach Goethes Ausspruch dem Grossen gegenüber nicht auskommt, bin ich am allerwenigsten gesonnen, in Abrede zu stellen, kann aber um so mehr davon nachlassen, je mehr ich auf ernstliche Schätzung des mir am Herzen liegenden Werkes treffe. Wie mir scheint, kommt eben hier alles auf dic doppeltc Erkenntnis an, erstlich, dass Gobineau mit dem schönsten Teile seines eigenen menschlichen Wesens sich in diesem seinem Werke verkörpert hat, und, was alsdann dem entspricht, dass im "Alexandre" jene natürliche Herzenssprache gesprochen wird, dic wir sonst in den meisten französischen Dramen nicht gewohnt 
sind. Das genügt mir. Dann kann man gewisse technische und dramatische Mängel des Stückes ruhig zugeben.

Nicht getäuscht scheine ich mich zum Glück vor allem in meinen Hoffnungen auf die Schule zu haben. Mehrere Referenten haben sich meine Empfehlung des Stückes für die Schullektüre ausdrücklich und eindringlich zu eigen gemacht, auch aus den Lehrerkreisen selbst sind mir warme Zustimmungen in diesem Sinne zugegangen, ja, ich habe die Freude gehabt, dass einzelne Gymnasien sogleich mit der Einführung vorangegangen sind, anderc sic für demnächst in Aussicht gestellt haben. So darf ich wohl den in meiner ersten Vorrede geäusserten Wunsch, dass dieses Heldenbild auf unseren höheren Schulen ein bleibendes Heim finden möge, jetzt bereits zur Hoffnung gesteigert wiederholen.

Verschiedene, teils brieflich, teils in öffentlichen Besprechungen mir unterbreitetc Vorschläge zu Änderungen und Verbesserungen -- ich nenne hier vor allem dic Namen der Herren Professor H. Müller in Heidelberg und Professor J. Scheidt in Hildesheim, denen ich mich für solche verbunden fühle - habe ich mit Dank benutzt, insbesondere auch der Aufforderung, im Interesse der Schule meiner Einleitung cine kurze biographische Skizze voranzuschicken, gern Folge gegeben.

Freiburg, Anfang Januar 1902.

Ludwig Schemann. 
